\title{
Effect of Mineral Fertilization on African Eggplant (Solanum spp.) Productivity in Côte d'Ivoire
}

\author{
Lassina Fondio, Mako François De Paul N'Gbesso and Noupé Diakaria Coulibaly \\ Vegetables and Proteagineous Crops Research Programme, Food Crops Research Station, National Agricultural Research Centre \\ (CNRA), Bouaké, 01 BP 633, Côte d'Ivoire
}

\begin{abstract}
Three African eggplant (Solanum spp.) varieties were assessed in six mineral manures doses $\mathrm{T}+1 / 2 \mathrm{~T}, \mathrm{~T}+1 / 4 \mathrm{~T}, \mathrm{~T}$, $\mathrm{T}-$ 1/4T, $\mathrm{T}-1 / 2 \mathrm{~T}$ and without fertilizer, with reference treatment $\mathrm{T}=300 \mathrm{~kg} / \mathrm{ha}$ of NPK 10-18-18 applied before transplanting $+\mathrm{a}$ mixture of $100 \mathrm{~kg} / \mathrm{ha}$ of urea and $200 \mathrm{~kg} / \mathrm{ha}$ of potassium sulphate at 30, 60 and $90 \mathrm{~d}$ after transplanting, to establish fertilization protocol for their cultivation. The experiment was laid out in split-plot design with three replications with varieties constituting the main factor and the fertilizer doses as secondary factor. The main observed parameters were the number of days to $50 \%$ flowering, the fruit number and weight per plant, individual fruit weight and fruit yields. As results, the interaction between varieties and fertilizer doses was significantly different only for the number of days to $50 \%$ of flowering $(P=0.0078)$ and the fruit number per plant $(P=0.0001)$, while any significant difference was observed for individual fruit weight $(P=0.64)$, fruit weight per plant $(P=$ $0.74)$ and fruit yields $(P=0.74)$. The difference among the fertilizers treatments was significant for the number of days to flowering, number of fruits per plant, fruit weight per plant and fruit yield for Aub33K/06Gn and Aub55N/10K, whereas any significant difference was observed for these parameters concerning Aub21N/06Du. Whatever the variety, there was not any significant difference among the fertilizers treatments for the individual fruit weight. For Aub33K/06Gn and Aub55N/10K cultivation, the fertilizers doses $\mathrm{T}-1 / 4 \mathrm{~T}$ and $\mathrm{T}-1 / 2 \mathrm{~T}$ are suggested, respectively, while a specific study is proposed for Aub21N/06Du. As perspective, economic studies are proposed to confirm the above suggested choices of fertilizers rates.
\end{abstract}

Key words: African eggplant, fertilization protocol, economic analysis.

\section{Introduction}

African eggplants (Solanum spp.) belonging to Solanaceae family are important vegetables for the populations in Côte d'Ivoire. Since 2004, national production of African eggplants is increasing. From 60,000 tonnes in 2004 , this production reached 81,000 tonnes in 2009, 103,000 tonnes in 2014 and it is estimated at 130,000 tonnes in 2020 [1]. The most cultivated species include S. aethiopicum L. Gilo group, S. anguivi Lam. and S. macrocarpon L.. In the whole country, African eggplants are grown and consumed by all the populations. Cultivation of African eggplants is high potential in Côte d'Ivoire because of their easiness to be grown. They are not exigent in soil and are suitable for many ecological

Corresponding author: Lassina Fondio, Ph.D., research field: establishing of vegetables production techniques. areas comparatively to tomato. African eggplants can be harvested many times and they are adapted to the several cooking techniques (sauces, pastes) of the country. Production and commercialization of these crops are insured by vulnerable people consisting of majority of women living in the rural and peri-urban areas of the country.

However, African eggplant development is facing many constraints, such as lack of improved varieties, low level of fertilizer use, poverty of growers, and negligence by the policy makers and scientists [2] mainly. Among these limiting factors, fertilization method is a serious issue because of the lack of a clear defined protocol of cultivation. As neglected crops, African eggplants are grown without a clear production protocol [3]. In the rural areas, eggplant farmers mostly do not apply any fertilizer, while in the urban sites, they use several manures comprising NPK 
or urea and non-composted poultry droppings without a determined rate and untimely application. In general for many indigenous vegetables species, there is no empirical recommendation on the optimum quantities of these manures and frequencies of their application for enhancing crop productivity [4]. Besides, limited information is available on African eggplants manure requirements for the optimal yield due to the lack of scientific studies on these traditional crops neglected by decision makers in Africa, particularly in Côte d'Ivoire. Therefore, to increase the productivity of African eggplants and contribute to enhancing farmers' livelihood through the country, it is vital to undertake research towards identification of the preferred nutrient requirements for these indigenous vegetables cultivation highly demanded by the population for their daily diets and generation of incomes. Hence, the objectives of this study were to determine the required doses of fertilizers (NPK, urea and potassium sulphate) in order to propose a suitable protocol for African eggplants cultivation in Côte d'Ivoire.

\section{Materials and Methods}

\subsection{Materials}

Three African eggplant varieties (Aub21N/06Du, Aub55N/10k and Aub33K/06Gn) selected by the National Agricultural Research Centre (CNRA) in Côte d'Ivoire, were used in this study. Aub21N/06Du and Aub55N/10k varieties belong to S. aethiopicum L. Gilo group and Aub33K/06Gn belongs to S. anguivi Lam.. All these varieties were selected for their bacterial wilt tolerance and high yielding potential from the local germplasm constituted by the CNRA through national prospection [3]. Aub21N/06Du is characterized by its cream white elongated fruits, while Aub55N/10k variety fruits are round and white at fresh harvesting stage [5]. Aub33K/06Gn as $S$. anguivi accessions is characterized by small size and elongate fruits.

\subsection{Methods}

\subsubsection{Experimentation Site}

The experiment was carried out from June to December 2012 at the Food Crops Research Station of Bouaké $\left(07^{\circ} 40^{\prime} 42.6^{\prime \prime}\right.$ north latitude, $05^{\circ} 05^{\prime} 52.2^{\prime \prime}$ west longitude and $403 \mathrm{~m}$ of altitude), located in the central part of Côte d'Ivoire. The soil of the experimental plots was classified as ferrallitic with $60 \%$ sand, $20 \%$ clay, $20 \%$ silt, $1.02 \%$ of organic carbon, $0.07 \%$ of total nitrogen, $86.68 \mathrm{ppm}$ of assimilable phosphorus, $0.59 \mathrm{meq} / 100 \mathrm{~g}$ of exchangeable potassium and $\mathrm{pH}$ (water) 5.46 .

This region is characterised by an instability of the rainfall pattern, varying according to the year between the south and north climate. In some years, two rainy seasons and two dry seasons are observed as in the southern regions, and in other years, one rainy season and one dry season can occur as in the north. Annual rainfall varies between $900 \mathrm{~mm}$ and 1,200 mm. Fig. 1 presents the monthly rainfall recorded in 2012 at the experimental station, where the annual rainfall was $1,172 \mathrm{~mm}$. During the trial which extended from June to December 2012, $773.3 \mathrm{~mm}$ of rain was registered.

\subsubsection{Agronomic Practices}

Seeds were sown on June 3rd, 2012, in the nursery beds built after a manual tillage of the soil. Before sowing, nursery beds were disinfected with Diafuran (Furadan 5G) at the rate of $50 \mathrm{~g} / \mathrm{m}^{2}$. The experiment field was ploughed to build ridges of $5 \mathrm{~m}^{2}$ (5 m long and $1 \mathrm{~m}$ wide), which were disinfected too with Diafuran and enriched with manure according to the treatments. A month aged seedlings (4-5 true leaves) were transplanted to the ridges on July 3rd, 2012 in double rows with spacing of $50 \mathrm{~cm}$ and $50 \mathrm{~cm}$ between plants in the rows. Experimental field was regularly weeded, and phytosanitary treatments were performed each $15 \mathrm{~d}$ with a mixture of Deltamethrin (Decis, $1 \mathrm{~L} / \mathrm{ha}$ ) and Manebe $(3.5 \mathrm{~kg} / \mathrm{ha})$ to protect the plants against pests and diseases. The trial was rainfed apart of the first week after the transplanting, where the 


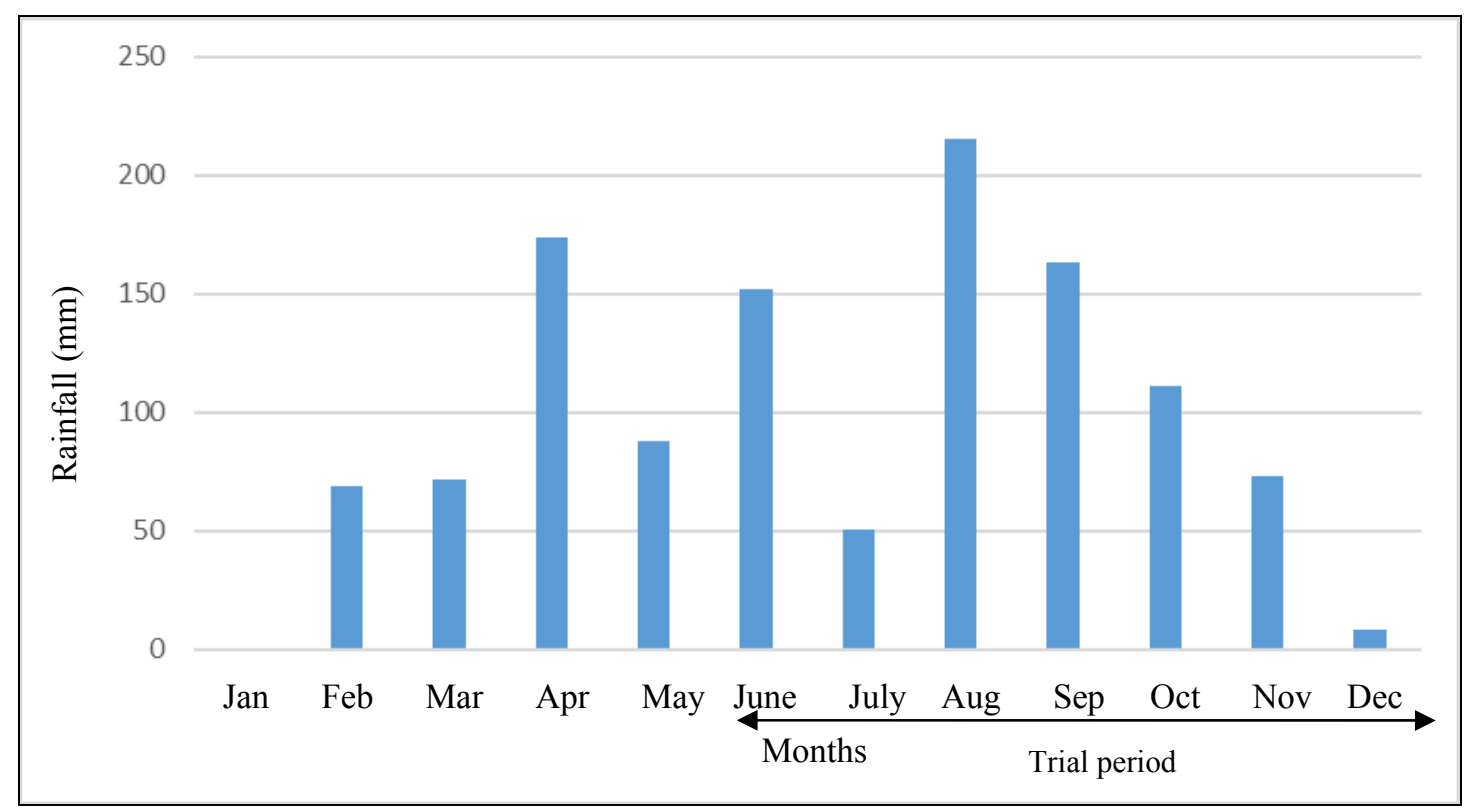

Fig. 1 Monthly rainfall recorded at the Food Crops Research Station of Bouake (Côte d'Ivoire) in 2012.

The trial period was June to December 2012.

seedlings were watered to facilitate their rooting. At the physiology maturity stage, fruits were manually harvested.

\subsubsection{Experimental Design}

The experiment was laid out in a split-plot design with three replications. Each plot consisted of two ridges of 10 plants. The main factor was Aub21N/06Du, Aub55N/10k and Aub33K/06Gn African eggplant varieties. The secondary factor was the fertilizer doses with six levels. The reference dose is the rate of fertilizers disseminated to the eggplant growers through the country by the National Agricultural Extension Service. Other fertilizers doses were obtained by taking the following proportions of the reference dose $(\mathrm{T})$, as indicated below:

(1) $\mathrm{T}_{0}$ : without fertilizer;

(2) $\mathrm{T}+1 / 2 \mathrm{~T}: 450 \mathrm{~kg} / \mathrm{ha}$ of NPK 10-18-18 applied before transplanting + a mixture of $150 \mathrm{~kg} / \mathrm{ha}$ of urea and $300 \mathrm{~kg} / \mathrm{ha}$ of potassium sulfate at 30,60 and $90 \mathrm{~d}$ after transplanting;

(3) $\mathrm{T}+1 / 4 \mathrm{~T}: 375 \mathrm{~kg} / \mathrm{ha}$ of NPK 10-18-18 applied before transplanting + a mixture of $125 \mathrm{~kg} / \mathrm{ha}$ of urea and $250 \mathrm{~kg} / \mathrm{ha}$ of potassium sulfate at 30,60 and $90 \mathrm{~d}$ after transplanting;
(4) $\mathrm{T}$ (reference treatment): $300 \mathrm{~kg} / \mathrm{ha}$ of NPK 10-18-18 applied before transplanting + a mixture of $100 \mathrm{~kg} / \mathrm{ha}$ of urea and $200 \mathrm{~kg} / \mathrm{ha}$ of potassium sulfate at 30,60 and $90 \mathrm{~d}$ after transplanting;

(5) $\mathrm{T}-1 / 4 \mathrm{~T}: 225 \mathrm{~kg} / \mathrm{ha}$ of NPK 10-18-18 applied before transplanting + a mixture of $75 \mathrm{~kg} / \mathrm{ha}$ of urea and $150 \mathrm{~kg} / \mathrm{ha}$ of potassium sulfate at 30,60 and $90 \mathrm{~d}$ after transplanting;

(6) $\mathrm{T}-1 / 2 \mathrm{~T}: 150 \mathrm{~kg} / \mathrm{ha}$ of NPK $10-18-18$ applied before transplanting + a mixture of $25 \mathrm{~kg} / \mathrm{ha}$ of urea and $100 \mathrm{~kg} / \mathrm{ha}$ of potassium sulfate at 30,60 and $90 \mathrm{~d}$ after transplanting.

\subsubsection{Observations Parameter}

Observations focused on the number of days to $50 \%$ of flowering expressed in days after transplanting (DAT), the total fruit number and weight per plant, individual fruit weight and fruit yields.

\subsection{Data Analysis}

All the collected data were analyzed with Statistical Analysis System (SAS) software. An analysis of variance (ANOVA) using general linear model (GLM) was first carried out. Treatments were compared using Duncan's range test at $P<0.05$. 


\section{Results}

General analysis of variance in Table 1 showed that interaction between varieties and fertilizer doses was high significant for the number of days to $50 \%$ of flowering $(P=0.0078)$ and fruit number per plant $(P$ 0.001). On the other hand, interaction between varieties and fertilizer doses was not significant for individual fruit weight $(P=0.64)$, fruit weight per plant $(P=0.74)$ and fruit yields $(P=0.74)$.

\subsection{Number of Days to $50 \%$ of Flowering}

The number of days to $50 \%$ of flowering was significantly different among the treatments for Aub33K/06Gn $(P=0.0165)$ and Aub55N/10K $(P=$ $0.0 .0076)$ varieties, while any significant difference $(P$ $=0.34$ ) was observed for Aub21N/06Du (Table 2). It was recorded that with Aub33K/06Gn variety, plants flowered early at 61.7 DAT with the highest amount of manure $(T+1 / 2 T)$ against $63.3,63.7,64,64.3$ and 66.3 for $\mathrm{T}, \mathrm{T}-1 / 4 \mathrm{~T}, \mathrm{~T}-1 / 2 \mathrm{~T}, \mathrm{~T}+1 / 4 \mathrm{~T}$ and $\mathrm{T}_{0}$, respectively. With Aub21N/066Du, plants flowered on average 56 DAT. With Aub55N/10K, plants flowered lately with the doses $\mathrm{T}_{0}, \mathrm{~T}$ and $\mathrm{T}+1 / 2 \mathrm{~T}$, and early with $\mathrm{T}+1 / 4 \mathrm{~T}, \mathrm{~T}-1 / 4 \mathrm{~T}$ and $\mathrm{T}-1 / 2 \mathrm{~T}$.

\subsection{Fruit Number per Plant}

As shown in Table 3, the fruit number per plant varied among the treatments according the varieties. With Aub33K/06Gn variety, the difference among fertilizers rates was significant $(P=0.0018)$, and the number of fruits per plant varied between 377.7 and 117 fruits per plant. The reference treatment (T) recorded 268.6 fruits per plant, not significantly different from $\mathrm{T}+1 / 4 \mathrm{~T}, \mathrm{~T}-1 / 4 \mathrm{~T}$ and $\mathrm{T}-1 / 2 \mathrm{~T}$.

For the variety Aub21N/06Du, there was no significant difference among the doses of fertilizers $(P$ $=0.35)$. The number of fruits per plant was 66.7 fruits in average.

With the variety Aub55N/10K, the difference among the doses of fertilizers was significant $(P=$ $0.0005)$ for the number of fruits per plant, which varied between 16.6 with $\mathrm{T}_{0}$ dose and 45 fruits with $\mathrm{T}$ $-1 / 2 \mathrm{~T}$ dose, not different from all other treatments, except $\mathrm{T}$ dose.

Table 1 Interaction between varieties and fertilizers doses.

\begin{tabular}{llllll}
\hline Source of variation & Days to flowering & Fruits number per plant & Individual fruit weight & Fruit weight per plant & Fruit yield \\
\hline Variety $\times$ doses & 0.0078 & 0.001 & 0.64 & 0.74 & 0.74 \\
Significance & $* *$ & $* *$ & NS & NS & NS \\
\hline
\end{tabular}

**: highly significant $(P<0.01)$; NS: not significant $(P>0.05)$.

Table 2 Number of days to $50 \%$ of flowering according to varieties and fertilizer doses.

\begin{tabular}{llll}
\hline \multirow{2}{*}{ Doses } & Varieties & \multicolumn{2}{c}{ Number of days to 50\% of flowering (DAT) } \\
\cline { 2 - 4 } & Aub33K/06Gn & Aub21N/06Du & Aub55N/10K \\
\hline $\mathrm{T}+1 / 2 \mathrm{~T}$ & $61.7^{\mathrm{c}}$ & $56.0^{\mathrm{a}}$ & $66.3^{\mathrm{a}}$ \\
$\mathrm{T}+1 / 4 \mathrm{~T}$ & $64.3^{\mathrm{ab}}$ & $54.7^{\mathrm{a}}$ & $65.0^{\mathrm{b}}$ \\
$\mathrm{T}$ & $63.3^{\mathrm{b}}$ & $56.3^{\mathrm{a}}$ & $69.0^{\mathrm{a}}$ \\
$\mathrm{T}-1 / 4 \mathrm{~T}$ & $63.7^{\mathrm{ab}}$ & $58.0^{\mathrm{a}}$ & $65.3^{\mathrm{b}}$ \\
$\mathrm{T}-1 / 2 \mathrm{~T}$ & $64.0^{\mathrm{ab}}$ & $56.0^{\mathrm{a}}$ & $65.0^{\mathrm{b}}$ \\
$\mathrm{T}_{0}$ & $66.3^{\mathrm{a}}$ & $55.7^{\mathrm{a}}$ & $69.0^{\mathrm{a}}$ \\
\hline Means & 64.0 & 56.1 & 66.7 \\
$P(\%)$ & 0.0165 & 0.3400 & 0.0076 \\
$\mathrm{CV}(\%)$ & 1.80 & 2.97 & 2.10 \\
\hline $\mathrm{T}(\mathrm{refo}$ & & & \\
\hline
\end{tabular}

$\mathrm{T}$ (reference treatment) $=300 \mathrm{~kg} / \mathrm{ha}$ of NPK 10-18-18 applied before transplanting + a mixture of $100 \mathrm{~kg} / \mathrm{ha}$ of urea and $200 \mathrm{~kg} / \mathrm{ha}$ of potassium sulfate at 30,60 and $90 \mathrm{~d}$ after transplanting; $\mathrm{T}_{0}=$ without fertilizer.

${ }^{\mathrm{a}-\mathrm{c}}$ Means in column with the same letters are not significantly different at 5\% (Duncan's range test). 
Table 3 Fruit number per plant according to the varieties and fertilizer doses.

\begin{tabular}{|c|c|c|c|}
\hline \multirow{2}{*}{ Fertilizer doses } & \multicolumn{3}{|c|}{ Fruit number per plant } \\
\hline & Aub33K/06Gn & Aub21N/06Du & Aub55N/10K \\
\hline $\mathrm{T}+1 / 2 \mathrm{~T}$ & $377.7^{\mathrm{a}}$ & $86.3^{\mathrm{a}}$ & $43.8^{\mathrm{a}}$ \\
\hline $\mathrm{T}+1 / 4 \mathrm{~T}$ & $249.8^{\mathrm{bc}}$ & $64.0^{\mathrm{a}}$ & $44.0^{\mathrm{a}}$ \\
\hline $\mathrm{T}$ & $268.6^{\mathrm{bc}}$ & $70.0^{\mathrm{a}}$ & $33.0^{\mathrm{b}}$ \\
\hline $\mathrm{T}-1 / 4 \mathrm{~T}$ & $307.2^{\mathrm{ab}}$ & $71.0^{\mathrm{a}}$ & $39.0^{\mathrm{ab}}$ \\
\hline $\mathrm{T}-1 / 2 \mathrm{~T}$ & $195.0^{\mathrm{cd}}$ & $69.5^{\mathrm{a}}$ & $45.0^{\mathrm{a}}$ \\
\hline $\mathrm{T}_{0}$ & $117.0^{\mathrm{d}}$ & $39.0^{\mathrm{a}}$ & $16.6^{\mathrm{c}}$ \\
\hline Means & 252.0 & 66.7 & 37.0 \\
\hline$P$ & 0.0018 & 0.3500 & 0.0005 \\
\hline CV (\%) & 20.6 & 35.5 & 14.5 \\
\hline
\end{tabular}

$\mathrm{T}$ (reference treatment) $=300 \mathrm{~kg} / \mathrm{ha}$ of NPK 10-18-18 applied before transplanting + a mixture of $100 \mathrm{~kg} / \mathrm{ha}$ of urea and $200 \mathrm{~kg} / \mathrm{ha}$ of potassium sulphate at 30,60 and $90 \mathrm{~d}$ after transplanting; $\mathrm{T}_{0}=$ without fertilizer.

${ }^{\mathrm{a}-\mathrm{d}}$ Means in column with the same letters are not significantly different at 5\% (Duncan's range test).

Table 4 Individual fruit weight according to the varieties and fertilizer doses.

\begin{tabular}{llll}
\hline \multirow{2}{*}{ Fertilizer doses } & Varieties & \multicolumn{3}{c}{ Individual fruit weight $(\mathrm{g})$} \\
\cline { 2 - 4 } & Aub33K/06Gn & Aub21N/06Du & Aub55N/10K \\
$\mathrm{T}+1 / 2 \mathrm{~T}$ & $6.7^{\mathrm{a}}$ & $35.7^{\mathrm{a}}$ & $57.7^{\mathrm{a}}$ \\
$\mathrm{T}+1 / 4 \mathrm{~T}$ & $15.6^{\mathrm{a}}$ & $39.0^{\mathrm{a}}$ & $57.7^{\mathrm{a}}$ \\
$\mathrm{T}-1 / 4 \mathrm{~T}$ & $11.7^{\mathrm{a}}$ & $35.7^{\mathrm{a}}$ & $58.2^{\mathrm{a}}$ \\
$\mathrm{T}-1 / 2 \mathrm{~T}$ & $8.2^{\mathrm{a}}$ & $35.1^{\mathrm{a}}$ & $55.7^{\mathrm{a}}$ \\
$\mathrm{T}_{0}$ & $12.1^{\mathrm{a}}$ & $34.8^{\mathrm{a}}$ & $51.1^{\mathrm{a}}$ \\
Means & $10.2^{\mathrm{a}}$ & $34.8^{\mathrm{a}}$ & $53.8^{\mathrm{a}}$ \\
$P$ & 10.7 & 35.8 & 55.7 \\
$\mathrm{CV}(\%)$ & 0.38 & 0.50 & 0.39 \\
\hline
\end{tabular}

$\mathrm{T}$ (reference treatment) $=300 \mathrm{~kg} / \mathrm{ha}$ of NPK 10-18-18 applied before transplanting + a mixture of $100 \mathrm{~kg} / \mathrm{ha}$ of urea and $200 \mathrm{~kg} / \mathrm{ha}$ of potassium sulphate at 30,60 and $90 \mathrm{~d}$ after transplanting; $\mathrm{T}_{0}=$ without fertilizer.

${ }^{a}$ Means in column with the same letters are not significantly different at 5\% (Duncan's range test).

\subsection{Individual Fruit Weight}

For the individual fruit weight, the difference between varieties was not significant among the varieties (Table 4). Aub33K/06Gn had the smallest fruits with $10.7 \mathrm{~g}$ against $35.8 \mathrm{~g}$ and $55.7 \mathrm{~g}$ for the other two varieties (Table 4).

\subsection{Fruit Weight per Plant}

The fruit weight per plant among the fertilizers doses differed significantly with Aub33K/06Gn $(P=$ 0.0006) and Aub55K/0610K $(P=0.0001)$ varieties and non-significantly $(P=0.37)$ with Aub21N/06Du (Table 5). With Aub33K/06Gn, the highest fruit weight per plant $(2,667.5 \mathrm{~g})$ was recorded by $\mathrm{T}+1 / 4 \mathrm{~T}$, followed by $\mathrm{T}+1 / 2 \mathrm{~T}(2,531.6 \mathrm{~g}), \mathrm{T}(2,270.8 \mathrm{~g})$ and $\mathrm{T}-1 / 4 \mathrm{~T}(2,144.3 \mathrm{~g})$, respectively. The doses $\mathrm{T}-1 / 2 \mathrm{~T}$ and $\mathrm{T}_{0}$ recorded the lowest fruit weight per plant with
$1,710.8 \mathrm{~g}$ and $962.5 \mathrm{~g}$, respectively, significantly different from the other treatments. With Aub21N/06Du, there was no difference among the fertilizers doses. An average of 2,186.5 g per plant was recorded. With Aub55N/10K, the highest fruit weight was obtained by $\mathrm{T}+1 / 4 \mathrm{~T}(2,546.6 \mathrm{~g})$, followed by $\mathrm{T}+1 / 2 \mathrm{~T}(2,487.5 \mathrm{~g}), \mathrm{T}-1 / 2 \mathrm{~T}(2,206.6$ $\mathrm{g})$, and $\mathrm{T}-1 / 4 \mathrm{~T}(2,169.6 \mathrm{~g})$, respectively. They are significantly different from $\mathrm{T}(1,936.6 \mathrm{~g})$ and $\mathrm{T}_{0}$ (889.1 g).

\subsection{Fruit Yield}

Fruit yield per hectare varied among the treatments according to the varieties (Table 6). For Aub33K/06Gn variety, the difference among the fertilizers doses was highly significant for Aub33K/06Gn $(P=0.0006)$ and Aub55N/10K $(P=0.0001)$, and 
Table 5 Fruit weight per plant according to the varieties and fertilizer doses.

\begin{tabular}{llll}
\hline \multirow{2}{*}{ Fertilizer doses } & Varieties & \multicolumn{3}{c}{ Fruit weight per plant $(\mathrm{g})$} \\
\cline { 2 - 4 } & Aub33K/06Gn & Aub21N/06Du & Aub55N/10K \\
$\mathrm{T}+1 / 2 \mathrm{~T}$ & $2,531.6^{\mathrm{a}}$ & $2,943.7^{\mathrm{a}}$ & $2,487.5^{\mathrm{a}}$ \\
$\mathrm{T}+1 / 4 \mathrm{~T}$ & $2,667.5^{\mathrm{a}}$ & $2,210.8^{\mathrm{a}}$ & $2,546.6^{\mathrm{a}}$ \\
$\mathrm{T}$ & $2,270.8^{\mathrm{ab}}$ & $2,467.5^{\mathrm{a}}$ & $1,936.6^{\mathrm{b}}$ \\
$\mathrm{T}-1 / 4 \mathrm{~T}$ & $2,144.3^{\mathrm{ab}}$ & $1,814.1^{\mathrm{a}}$ & $2,169.6^{\mathrm{ab}}$ \\
$\mathrm{T}-1 / 2 \mathrm{~T}$ & $1,710.8^{\mathrm{b}}$ & $2,373.3^{\mathrm{a}}$ & $2,206.6^{\mathrm{ab}}$ \\
$\mathrm{T}_{0}$ & $962.5^{\mathrm{c}}$ & $1,310.0^{\mathrm{a}}$ & $889.1^{\mathrm{c}}$ \\
\hline Means & $2,047.9$ & $2,186.5$ & $2,039.3$ \\
$P$ & 0.0006 & 0.3700 & 0.0001 \\
$\mathrm{CV}(\%)$ & 15.4 & 14.8 & 12.6 \\
\hline $\mathrm{T}$ (reference treatment) $=300 \mathrm{~kg} / \mathrm{ha}$ of NPK 10-18-18 applied before transplanting + a mixture of $100 \mathrm{~kg} / \mathrm{ha}$ of urea and $200 \mathrm{~kg} / \mathrm{ha}$ of \\
potassium sulphate at 30, 60 and 90 d after transplanting; $\mathrm{T}_{0}=$ without fertilizer.
\end{tabular}

Table 6 Fruit yield according to the varieties and fertilizer doses.

\begin{tabular}{|c|c|c|c|}
\hline \multirow{2}{*}{ Fertilizer doses } & \multicolumn{3}{|c|}{ Fruit yield (ton/ha) } \\
\hline & Aub33K/06Gn & Aub21N/06Du & Aub55N/10K \\
\hline $\mathrm{T}+1 / 2 \mathrm{~T}$ & $50.6^{\mathrm{a}}$ & $58.8^{\mathrm{a}}$ & $49.7^{\mathrm{a}}$ \\
\hline $\mathrm{T}+1 / 4 \mathrm{~T}$ & $53.3^{\mathrm{a}}$ & $44.2^{\mathrm{a}}$ & $50.9^{\mathrm{a}}$ \\
\hline $\mathrm{T}$ & $45.4^{\mathrm{ab}}$ & $49.3^{\mathrm{a}}$ & $38.7^{\mathrm{b}}$ \\
\hline $\mathrm{T}-1 / 4 \mathrm{~T}$ & $42.8^{\mathrm{ab}}$ & $36.3^{\mathrm{a}}$ & $43.4^{\mathrm{ab}}$ \\
\hline $\mathrm{T}-1 / 2 \mathrm{~T}$ & $34.2^{\mathrm{b}}$ & $47.5^{\mathrm{a}}$ & $44.1^{\mathrm{ab}}$ \\
\hline & $19.2^{\mathrm{c}}$ & $26.2^{\mathrm{a}}$ & $17.8^{\mathrm{c}}$ \\
\hline Means & 40.9 & 43.7 & 40.8 \\
\hline$P$ & 0.0006 & 0.3700 & 0.0001 \\
\hline CV (\%) & 15.3 & 15.7 & 12.6 \\
\hline
\end{tabular}

$\mathrm{T}$ (reference treatment) $=300 \mathrm{~kg} / \mathrm{ha}$ of NPK 10-18-18 applied before transplanting + a mixture of $100 \mathrm{~kg} / \mathrm{ha}$ of urea and $200 \mathrm{~kg} / \mathrm{ha}$ of potassium sulphate at 30,60 and $90 \mathrm{~d}$ after transplanting; $\mathrm{T}_{0}=$ without fertilizer.

${ }^{\mathrm{a}-\mathrm{c}}$ Means in column with the same letters are not significantly different at $5 \%$ (Duncan's range test).

non-significant for Aub21N/06Du $(P=0.37)$. With Aub33K/06Gn, fruit yield was high in treatments of $\mathrm{T}$ $+1 / 2 \mathrm{~T}, \mathrm{~T}+1 / 4 \mathrm{~T}, \mathrm{~T}$ and $\mathrm{T}-1 / 4 \mathrm{~T}$, and it was less in treatments of $\mathrm{T}-1 / 2 \mathrm{~T}$ and $\mathrm{T}_{0}$. With Aub21N/06Du, there was no significant among the treatments. An average fruit yield of 43.7 ton/ha was registered. With Aub55N/10K, the plants that received treatments of $\mathrm{T}$ $+1 / 2 \mathrm{~T}, \mathrm{~T}+1 / 4 \mathrm{~T}, \mathrm{~T}-1 / 4 \mathrm{~T}$ and $\mathrm{T}-1 / 2 \mathrm{~T}$ produced the high fruit yield of 49.7, 50.9, 43.4 and 44.1 ton/ha, respectively. The least fruit yield of 38.7 ton/ha and 17.8 ton/ha was produced by plants that received $\mathrm{T}$ and $\mathrm{T}_{0}$ treatments, which were different.

\section{Discussion}

A significant interaction between eggplant varieties and fertilizer doses for the number of days to $50 \%$ of flowering and fruit number per plant could mean that the expression of these parameters depends on both varieties genetics and fertilizers rates. Similar results were reported by Shahein et al. [6], showing significant interaction between organic fertilizers and hybrids on early and fruit number per plant of bell pepper. While, the lack of significant interaction between eggplant varieties and fertilizers rates for the individual fruit weight and fruit yields could mean that the expression of these parameters depend mainly on whether variety or fertilizers. These observations were not in agreement with Shahein et al. [6], who established significant interaction between fertilizers and bell pepper hybrids on fruit yield.

\subsection{Number of Days to 50\% of Flowering}

The significant effect among fertilizers rates on the number of days to flowering in the plants of 
Aub33K/06Gn and Aub55N/10K could indicate that these varieties are more sensitive to mineral nutrients supplying than Aub21N/06Du, for which the difference among fertilizers doses was not significant. But, the earliness of flowering in plants of Aub33K/06Gn that received the highest amount of manure $(T+1 / 2 T)$ may be as the result of the higher vegetative growth, resulting from the increased nutrients supplied. This earliness of flowering induced by the highest amount of fertilizers in plant is not in accordance with the findings in Ref. [7], where nutrient application was reported to delay anthesis in eggplant and tomato. By cons, with the variety Aub21N/06Du, the response of plants to fertilizer inputs on the induction of flowering is low, resulting in the high influence of the genetics on this variety flowering. It was reported that tomato varieties differed in their performance, which is controlled by interplay of both genetic and the environment [8].

\subsection{Fruit Number per Plant, Fruit Weight per Plant and Fruit Yield}

The significant difference observed among the fertilizers treatments in the eggplant of Aub33K/06Gn Aub55N/10K varieties for the number of harvested fruits per plant, the fruit weight per plant and the fruit yield can be explained by the fact that these varieties had a high capacity to assimilate nutrients and to use them for their physiological activities. Meanwhile, the highest number of fruit per plant, fruit weight per plant and fruit yield recorded by the highest amount of fertilizers rates could be explained by the favourable impact of fertilization on fruit process production [9, 10]. This increase in productivity of plants according to fertilizer rates was also shown by Vijaya and Halakshmi [11]. Concerning Aub33K/06Gn variety, the lack of significant difference among the following treatments $\mathrm{T}+1 / 2 \mathrm{~T}, \mathrm{~T}+1 / 4 \mathrm{~T}, \mathrm{~T}$ and $\mathrm{T}-1 / 4 \mathrm{~T}$ means these fertilizers doses induce the same agronomic performance in the plants, suggesting the choice of the lowest amount of fertilizers, i.e., $\mathrm{T}-1 / 4 \mathrm{~T}$ as the best mineral manure rate for this variety cultivation. As regarding Aub55N/10K, the absence of significant difference among $\mathrm{T}+1 / 2 \mathrm{~T}, \mathrm{~T}+1 / 4 \mathrm{~T}, \mathrm{~T}-1 / 4 \mathrm{~T}$ and $\mathrm{T}$ $-1 / 2 \mathrm{~T}$ treatments for the fruit number per plant, fruit weight per plant and fruit yield could suggest the choice of $T-1 / 2 T$ fertilizers dose as the appropriate mineral manure rate for this African eggplant cultivation.

Concerning Aub21N/06Du, the lack of significant difference among the fertilizers treatments for the number of days to $50 \%$ of flowering, the number fruits per plant, fruit weight per plant and fruit yield could indicate that this variety did not react easily to the fertilization treatments. This result could suggest to undertake specific studies on the mineral nutrition of this variety in order to provide clear advice on the fertilization technique to the farmers.

The absence of a significant difference among the fertilizers doses for the individual fruit weight whatever the variety could mean that this parameter is mainly linked to the genotype of each variety. There are some varieties characterized by the smallness of their fruits size and other by the largeness. This result is in harmony with findings on bell pepper, of which the differences in yield component were reported due to the variety genotype $[12,13]$.

\section{Conclusions}

This study on the effect of fertilizers doses on the production of three eggplant varieties showed that the interaction between varieties and fertilizers doses was significant for the number of days to $50 \%$ of flowering and fruit number per plant, whereas it was not significant for individual fruit weight, fruit weight per plant and fruit yield.

For Aub33K/06Gn variety cultivation, the study suggested the choice of the fertilizers dose $T-1 / 4 \mathrm{~T}$ (225 kg/ha of NPK10-18-18 applied before transplanting + a mixture of $75 \mathrm{~kg} / \mathrm{ha}$ of urea and 150 $\mathrm{kg} / \mathrm{ha}$ of potassium sulphate at 30,60 and $90 \mathrm{~d}$ after transplanting) as the suitable mineral manure rate. 
Concerning Aub21N/06Du, because of the lack of a clear reaction of this variety to the fertilization treatments, the study suggested to undertake specific studies on the mineral nutrition of this variety in order to establish an appropriate fertilization protocol for its cultivation in the country.

For Aub55N/10K, the absence of significant difference among $\mathrm{T}+1 / 2 \mathrm{~T}, \mathrm{~T}+1 / 4 \mathrm{~T}, \mathrm{~T}-1 / 4 \mathrm{~T}$ and $\mathrm{T}$ $-1 / 2 \mathrm{~T}$ treatments for the yield components suggested the choice of $\mathrm{T}-1 / 2 \mathrm{~T}$ fertilizers dose $(150 \mathrm{~kg} / \mathrm{ha}$ of NPK10-18-18 applied before transplanting $+\mathrm{a}$ mixture of $25 \mathrm{~kg} / \mathrm{ha}$ of urea and $100 \mathrm{~kg} / \mathrm{ha}$ of potassium sulphate at 30,60 and $90 \mathrm{~d}$ after transplanting) as the appropriate mineral manure rate for this African eggplant cultivation.

Meanwhile, an economic study could be proposed as perspective to confirm the suggested choices of fertilizers treatments for the different eggplant varieties cultivation and to pursue the mineral nutrition studies on Aub21N/06Du in order to establish a suitable fertilization protocol for its cultivation in the country. In relation to the reference treatment, adoption of the above suggested doses would reduce the quantity of the mineral manure advised to the farmers.

\section{References}

[1] Ministry of Agriculture. 2014. "National Strategy for the Food Crops Development Different from Rice." DGPSA/UE, Abidjan, Côte d'Ivoire.

[2] Fondio, L., Kouamé, C., N’zi, J. C., Mahyao, A., Agbo, E., and Djidji, A. H. 2007. "Survey of Indigenous Leafy Vegetable in the Urban and Peri-urban Areas of Côte d'Ivoire." In Indigenous Vegetables and Legumes: Prospects for Fighting Poverty, Hunger and Malnutrition, edited by Chadha, M. L., Kuo, G., and Gowda, C. L. L. Hyderabad, India: Acta Horticulturae, 287-9.

[3] Fondio, L., N'tamon, N. L., Hala, N. F., and Djidji, A. H. 2008. "Agronomic Assessment of Six African Eggplant Cultivars (Solanum spp.) from the New Vegetable Crop Collection of the CNRA." Agronomie Africaine 20 (1): 69-79.
[4] Okokoh, S. J., and Bisong, B. W. 2011. "Effect of Poultry Manure and Urea-N on Flowering Occurrence and Leaf Productivity of Amaranthus cruentus." J. Appl. Sci. Environ. Manage. 15 (1): 13-5.

[5] CNRA. 2016. Catalogue of Improved Food Crops Varieties. Abidjan, Côte d'Ivoire: CNRA, 52.

[6] Shahein, M. M., El-Sayed, S. F., Hassan, H. A., and Abou-El-Hassan, S. 2015. "Producing Sweet Pepper Organically Using Different Sources of Organic Fertilizers under Plastic House Conditions." In Proceedings of International Conference on Advances in Agricultural, Biological and Environmental Sciences (AABES-2015), 72-8.

[7] Aminifard, M. H., Aroiee, H., Fatemi, H., Ameri, A., and Karimpour, S. 2010. "Responses of Eggplant (Solanum melongena L.) to Different Rates of Nitrogen under Field Conditions." J. Cent. Eur. Agric. 11 (4): 453-8.

[8] Ishah, A. S., Amans, E. B., Odion, E. C., and Yusuf, A. A. 2014. "Growth Rate and Yield of Two Tomato Varieties (Lycopersicon esculentum Mill) under Green Manure and NPK Fertilizer Rate in Samaru, Northern Guinea Savanna." International Journal of Agronomy. doi: 10.1155/2014/932759.

[9] Ogar, E. A., and Asiegbu, J. E. 2005. "Effects of Fertilizer Rates and Cutting Frequency on the Marketable Vegetables and Pod Yields in Fluted Pumpkin in Southeastern, Nigeria.” Agro-Science 4 (1): 66-9.

[10] Aujla, M. S., Thind, H. S., and Buttar, G. S. 2007. "Fruit Yield and Water Use Efficiency of Eggplant (Solanum melongena L.) as Influenced by Different Quantities of Nitrogen and Water Applied through Drip and Furrow Irrigation." Scientia Horticulturae 112 (2): 142-8.

[11] Vijaya, K. S., and Halakshmi, S. 2011. "Response of Eggplant (Solanum melongena L.) to Integrated Nutrient Management Amended Soil." Int. J. Scientific and Engineering Res. 2 (8): 1-8.

[12] Geleta, L. F., Labuschagne, M. T., and Viljoen, C. D. 2005. "Genetic Variability in Pepper (Capsicum annuum L.) Estimated by Morphological Data and Amplified Fragment Length Polymorphism Markers." Biodiversity and Conservation 14 (10): 2361-75.

[13] Deepa, N., Kaur, C., Singh, B., and Kapoor, H. C. 2006. "Antioxidant Activity in Some Red Sweet Pepper Cultivars." Journal of Food Composition and Analysis 19 (6-7): 572-8. 